\title{
FAILURES AND RELIABILITY IN HAWTS OPERATING IN MOUNTAINOUS AREAS, OPEN SEA AND IN HARSCH CLIMATE SITES
}

\author{
Giovanni Maria De Pratti - "La Sapienza" University of Rome - DIMA ${ }^{1}$
}

\begin{abstract}
Recently, offshore wind plants, as Horn's Riv one, have reached a remarkable interest and development. In these sites, HAWT's blades experiment corrosion, erosion and fouling and, at higher latitudes, icing conditions too, as in mountainous areas and in harsch climate sites. The operative conditions may influence the machine damages and they may occur as consequence of erosion, corrosion, fouling, icing, exfoliation caused by the above mentioned environmental conditions. The paper reports about data collection about failures occurred to HAWTS operating in offshore, mountainous and harsch climate sites in last ten years. Particularly, the damage occurred to blades, gears and bearings have been examined and the consequences analysed. The occurred failures are examined and the reliability of WTGs is assessed by appropriate models and analysis. The results are com pared to literature data and they may be very useful in programmable maintenance and in predictable one. Reliability analysis may be also useful to increase energy production.
\end{abstract}

\section{Introduction}

Wind is one of the most important renewable energy sources and at the present time there are many wind farms in onshore and offshore sites.

Recently, offshore wind plants, as Horn's Riv one, have reached a remarkable interest and development. In these sites, HAWT's (Horizontal Axis Wind Turbine) blades experiment corrosion, erosion and fouling and, at higher latitudes, icing conditions too, as in mountainous areas and in harsch climate sites.

\footnotetext{
${ }^{1}$ Corresponding Author: giovannimaria.depratti@uniroma1.it
} 
The operative conditions may influence the machine damages and they may occur as consequence of erosion, corrosion, fouling, icing, exfoliation caused by the above mentioned environmental conditions [8].

Reliability analysis may be very useful to reach a better knowledge concerning of the behaviour of WTG (Wind Turbine Generator) system in the above mentioned sites and conditions [10]. An important aspect is related to the location of the wind farm. In fact, today, many wind farms are built offshore for different reasons: the wind speed is more powerful and constant due to the absence of obstacles, and visual, environmental, and acoustic impact is cut down. Nevertheless, the maintenance cost is higher than the onshore wind farm. A good stochastic model can help the planning of preventive maintenance suggesting when is suitable to execute the maintenance operation. This is possible by analyzing what happens when a particular transition between two different states may occur.

Evaluations about WTGs failure show that modern onshore WTs (Win d Turbine) in Europe achieve a high availability of 95-99\% [6]. However, despite WT technology progress, in terms of economy and performance, WT reliability seem to be declined with growing turbine size. Electrical and electronic subassemblies, in particular, fail more frequently, leading to higher failure rates for WTs of higher complexity. An increasing number of failures cause unplanned downtimes up to 10 times per turbine per year, resulting in high maintenance effort and production loss [5].

While the performance and the efficiency of wind turbines and their energy yields have been improved with time, their reliability still needs improvement, particularly when considering their deployment offshore [9].

Many factors may influence the WTGs failure rate, such as wind speed, wind turbine design and climate conditions: these aspects should be part of every reliability analysis and assessment [8]. In the Tab. 1 data about these aspects have been collected.

The shown data have been collected in different way: some have been collected, directly by the Author, on machines or wind farms, during mainteinance operation in several Italian sites as Collarmele or Tocco da Casauria (in Abruzzi Region) and Frosolone (in Molise Region) and ever in mountainous areas, others have been collected by mainteinance journal of WTG in German sites or during specific inspection, while only for a group of German wind farms the data have been produced by a previous paper [4].

The modelling of reliability structure of WTG has been developed by analysing many WTG layout. 
Table 1. Climate conditions and type of site from [8]

Criteria for the climatic region classifications for Germany.

\begin{tabular}{|c|c|c|c|c|}
\hline 1st & 2nd & 3 rd & Description & Criteria \\
\hline $\mathrm{C}$ & - & - & Temperate & Thot $\geq 10 \& 0<$ Tcold $<18$ \\
\hline- & $\mathrm{s}$ & - & - Dry Summer & Psdry $<40 \&$ Psdry $<$ Pwwet $/ 3$ \\
\hline - & w & - & - Dry Winter & Pwdry $<$ Pswet $/ 10$ \\
\hline- & $\mathrm{f}$ & - & - Without dry season & Not $(\mathrm{Cs})$ or $(\mathrm{Cw})$ \\
\hline - & - & a & - Hot Summer & Thot $\geq 22$ \\
\hline - & - & b & - Warm Summer & Not (a) \& Tmon10 $\geq 4$ \\
\hline - & - & c & - Cold Summer & $\operatorname{Not}(\mathrm{a}$ or $\mathrm{b}) \& \mathrm{Tmon} 10<4$ \\
\hline $\mathrm{D}$ & - & - & Cold & Thot $\geq 10 \&$ Tcold $\leq 0$ \\
\hline- & s & - & - Dry Summer & Psdry $<40 \&$ Psdry $<$ Pwwet $/ 3$ \\
\hline - & w & - & - Dry Winter & Pwdry $<$ Pswet $/ 10$ \\
\hline - & $\mathrm{f}$ & - & - Without dry season & Not (Ds) or (Dw) \\
\hline - & - & a & - Hot Summer & Thot $\geq 22$ \\
\hline - & - & b & - Warm Summer & Not (a) \& Tmon $10 \geq 4$ \\
\hline - & - & c & - Cold Summer & $\operatorname{Not}(a, b$ or $d)$ \\
\hline - & - & d & - Very Cold Winter & Not $(\mathrm{a}$ or $\mathrm{b})$ \& Tcold $<-38$ \\
\hline
\end{tabular}

Note: $T_{\text {hot }}=$ temperature of the hottest month, $T_{\text {cold }}=$ temperature of the coldest month, $T_{\text {mon10 }}=$ number of months where the temperature is above $10, \mathrm{P}_{\mathrm{dry}}=$ precipitation of the driest month, $\mathrm{P}_{\text {sdry }}=$ precipitation of the driest month in summer, $\mathrm{P}_{\mathrm{wdry}}=$ precipitation of the driest month in winter, $\mathrm{P}_{\text {swet }}=$ precipitation of the wettest month in summer, $\mathrm{P}_{\text {wwet }}=$ precipitation of the wettest month in winter

\section{Cfa: Temperate-without dry season-hot summer \\ $\mathrm{Cfb}$ : Temperate-without dry season-warm summer \\ Dfb: Cold-without dry season-warm summer \\ Dfc: Cold-without dry season-cold summer}

Particularly, it seems that WTG design complexity may show an higher failure rate than others and this is more evident in electric systems, electronic control, sensors, yaw systems, rotor blades, generator and drive train [2].

The specific climate site conditions may be very useful in understanding the failure causes [8].

\section{Reliability of hawts}

Reliability is defined [2] as the ability to perform as required, without failure, for a given time interval under given conditions, whereas availability is defined as the ability to be in a state to perform as required in the International Electrotechnical Commission (IEC) 60050 standards. Particularly, reliability is the probability of a device performing its purpose adequately for the period of time intended under the operating conditions encountered, while availability is the probability of finding a system in the operating state at some time into the future as in [4]. [5] and [7]. 
Under the mathematical point of view, reliability may be modelled as in the following equations as in [4] and [7].

Reliability function, from the MTBF point of view, may be:

$$
R(t)=e^{-t / m}
$$

where $\mathrm{R}(\mathrm{t})$ is reliability as function of time ( $\mathrm{t}$ ) and $\mathrm{m}$ is MBTF (it depends from failure rate), assessed by Ireson's criteria [7];

from a global point of view, reliability may be assessed as in the following eqs. (2) and (3):

$$
P=\frac{\left((\mu+1 / T) \cdot\left(D \cdot \lambda+P_{S}\right)\right.}{\mu \cdot[D \cdot(\mu+1 / T)+1]+D \cdot \lambda \cdot(\mu+1 / T)+P_{S} / T}
$$

where [4] $\mu$ is the repairing rate, $\lambda$ is the failure rate, $\mathbf{T}$ the time duration of the cycle, $\mathbf{D}$ the rate of operative running time vs. starting up numbers and $\mathbf{P}_{\mathbf{S}}$ the probability of a failure during the start up and, at last, $\mathbf{P}$ the conditioned unavailability.

Therefore reliability evaluation is represented by

$$
\mathbf{R}(\mathbf{t})^{*}=\mathbf{1 - P}
$$

To assess reliability of a system, the system structure function may be very useful. This structure has been analysed in the Figs.1, 2, 6, 7 and 8 where every block is a component or a subsystem. Taking into account the system shown in Fig. 1 (system structure of an HAWT) the corresponding reliability may be modelled as:

$$
\Phi=\prod_{1}^{n} X_{j}
$$

$\Phi$ is the reliability function (expressed as structure system function) related to the structure and $\mathrm{X}_{\mathrm{j}}$ is the generic value of the component " $\mathrm{j}$ " reliability. In this way reliability may be assessed at first on the basis of machine structure or rather the axis line of the machine.

Obviously, $\mathrm{X}_{\mathrm{j}}$ contributes in different way if the component is "in series" (in succession) or "in parallel" (in redundancy) and the corresponding contribute $X_{j}$ to the $\Phi$ function is:

$\mathrm{X}_{\mathrm{j}}^{*} \mathrm{X}_{\mathrm{k}}$ (components in "series")

$$
\left[1-\left(1-\mathrm{X}_{\mathrm{j}}\right) *\left(1-\mathrm{X}_{\mathrm{k}}\right)\right](\text { components "in parallel”) }
$$


Figure 1. An example of HAWT structure from reliability point of view

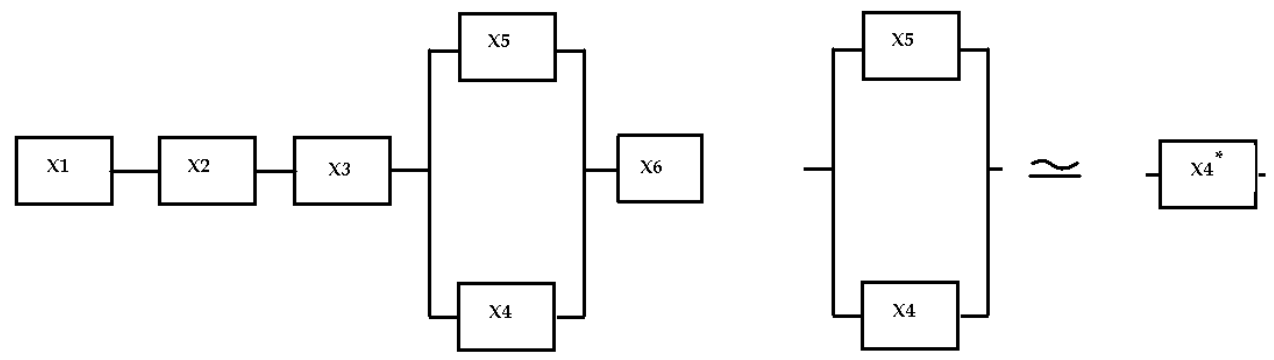

In the Fig. 1 the succession of blocks reproduces the axis line consisting of: $1=$ rotor blades and hub, $2=$ driving shaft, $3=$ gearbox, $4=$ mechanical brake, $5=$ hydraulic brake, $4 *=$ brakes "in parallel".

The reliability analysis and assessment may be very useful in projecting mainteinance procedures as shown in Fig. 2 that has been taken with modification from [10].

Figure 2. Reliability and mainteinance procedures

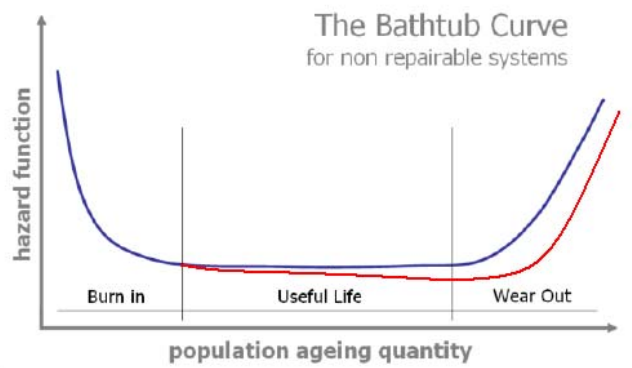

(a)

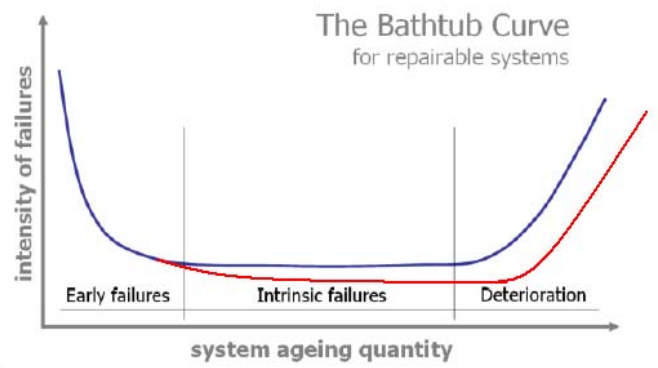

(b)

— The bathtub curve (a) for non repairable systems and (b) for repairable systems .

— The corresponding curves in the case of mainteinance based on reliability analysis introduction

In the Fig. 1 the modification consists of the "red line" representing the corresponding curve in the case of mainteinance procedures developed as suggested by reliability analysis.

To analyse, in a correct way, the structure of an HAWT, it is very important to describe the components and the subsystems. They are collected in the Table 2 from [8]. 
Table 2. Subsystems and components of HAWT from [8]

Subsystems and assemblies of wind turbines

\begin{tabular}{cc}
\hline Subsystems of Wind Turbines & Components of Wind Turbines \\
\hline Hub & Hub body, pitch mechanism, pitch bearings \\
Structure & Foundations, tower/tower bolts, nacelle frame, nacelle cover and ladder \\
Rotor Blades & Blade bolts, blade shell and aerodynamic brakes \\
Mechanical Brake & Brake disc, brake pads and brake shoe \\
Drive Train & Rotor bearings, drive shafts and couplings \\
Gearbox & Bearings, whels, gear shaft and sealings \\
Generator & Generator windings, generator brushes and bearings \\
Yaw System & Yaw bearings, yaw motor, wheels and pinions \\
Sensors & Anemometer/wind vane, vibration switch, temperature, oil pressure switch, \\
power sensor and revolution counter & \\
Hydraulic System & Hydraulic pump, pump motor, valves and hydraulic pipes/hoses \\
Electrical System & Converter, fuses, switches and cables/connections \\
Control System & Electronic control unit, relay, measurement cables and connections \\
\hline
\end{tabular}

Every failure may produce a downtime with a resulting lost in energy production or a lower power generation vs. rated power. The lost in power generation have a corresponding lost in energy productions and this may be modelled as in [8] by the equation:

$$
\mathrm{LEP}=\mathrm{CF} \cdot \mathrm{P}_{\mathrm{WTG}} \cdot \mathrm{DTF} \cdot \mathrm{AFR}
$$

where LEP is the lost energy production $(\mathrm{kWh}), \mathrm{CF}$ the capacity factor, $\mathrm{P}_{\mathrm{WTG}}$ the WTG rated power $(\mathrm{kW})$, DTF the downtime per failure $(h)$ and AFR the annual failure rate.

From this point of view the analysis of downtime may be very important in assessing lost energy production from several wind farms.

The first stage of the present work has been a filed study carried out measuring the reliability of existing WTGs at several operational wind farms in Germany and Italy, using WTGs data as: 10Minute average SCADA DATA, fault/alarm logs, work orders/service reports and O\&M contractor reports.

As shown in Figs. 3-4-5-6-7-8, some structure schemes may be very useful in analysing the above mentioned data, but to analyse system reliability in the better way possible we ought to remember the structure of systems as showed in Fig. 6 and the following formula by [10] about the average failure rate for sub-assemblies that has been calculated over the entire recording period according to:

$$
\lambda=\frac{\sum_{i} n_{i}}{T-\sum_{k} D_{i}}
$$


where $i$ is index counting the number of sub-assemblies failures, $n$ is the number of sub-assembly failures, $T$ is the total length of the recording period, $k$ is the index counting the total number of downtimes and, obviously, $D$ is downtime.

Figure 3. Structure of an HAWT-drive train
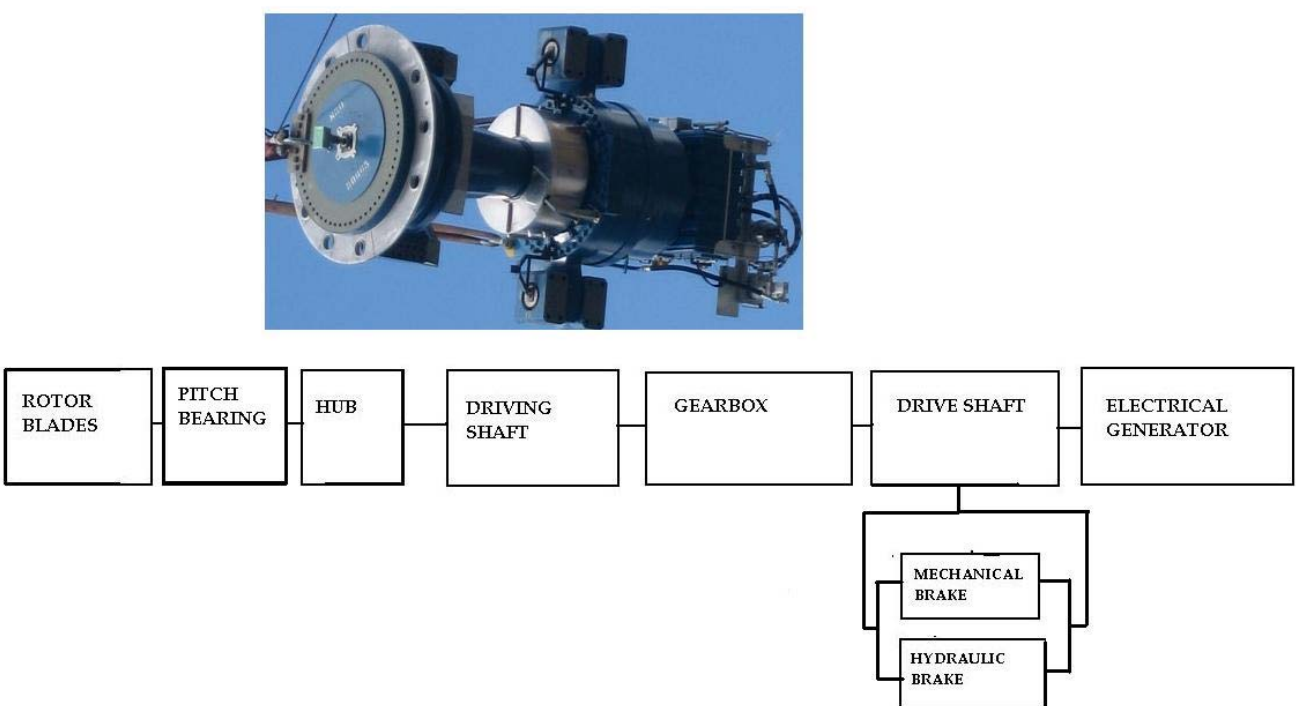
Figure 4. HAWT's Structure (presence of gearbox) [11]

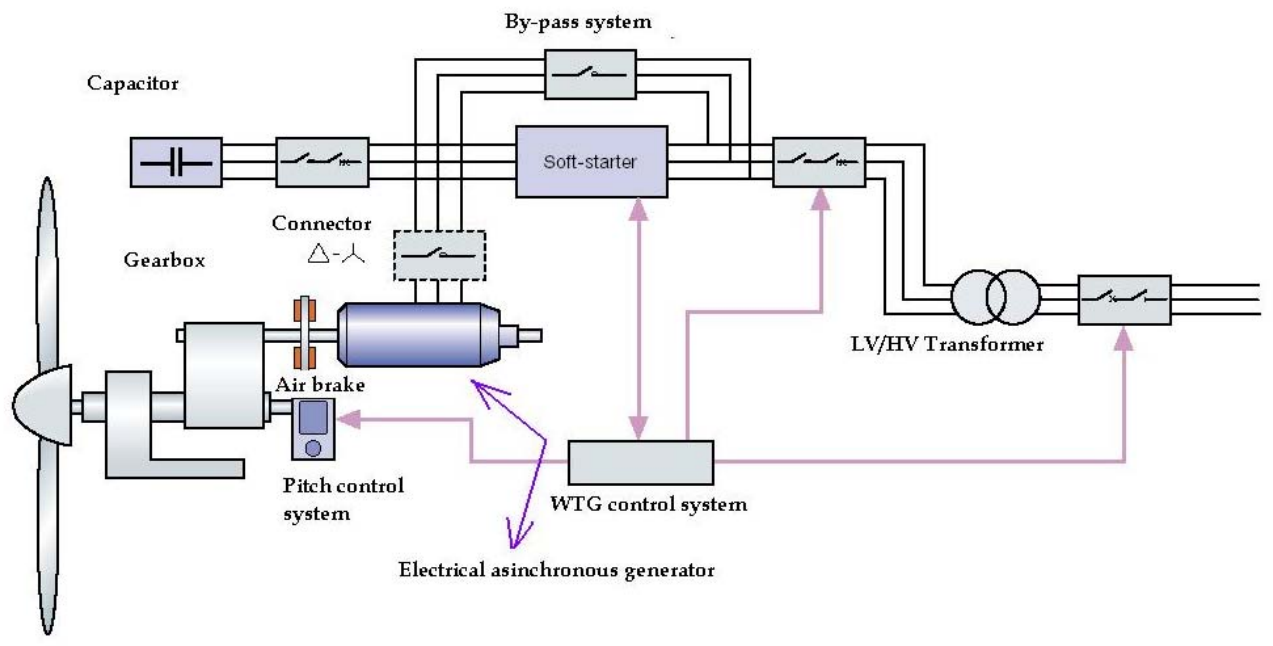

Figure 5. Gearless HAWTS's Structure [11]

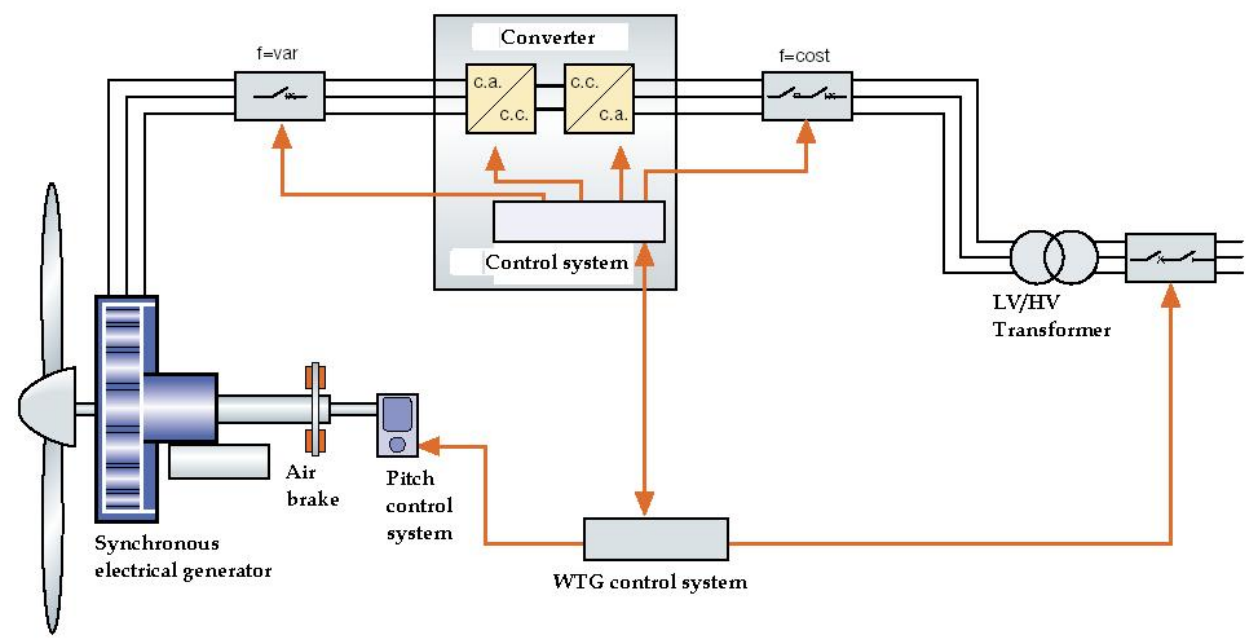


Figure 6. Structure of an hawt system revised from [10]

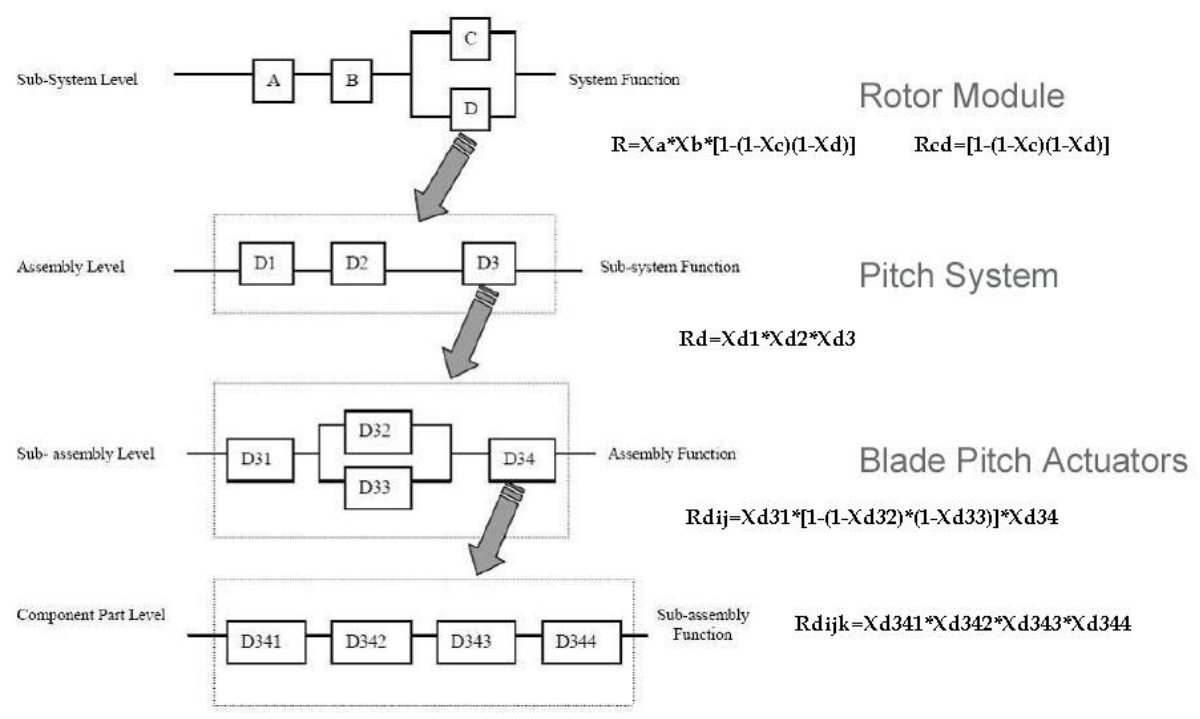

The numbers are related to component-type

$\mathbf{R}=$ Sub-system Reliability $\quad X_{\mathbf{j}}=$ Specific Component Reliability 
Figure 7. An example of hawt structure revised from [4]

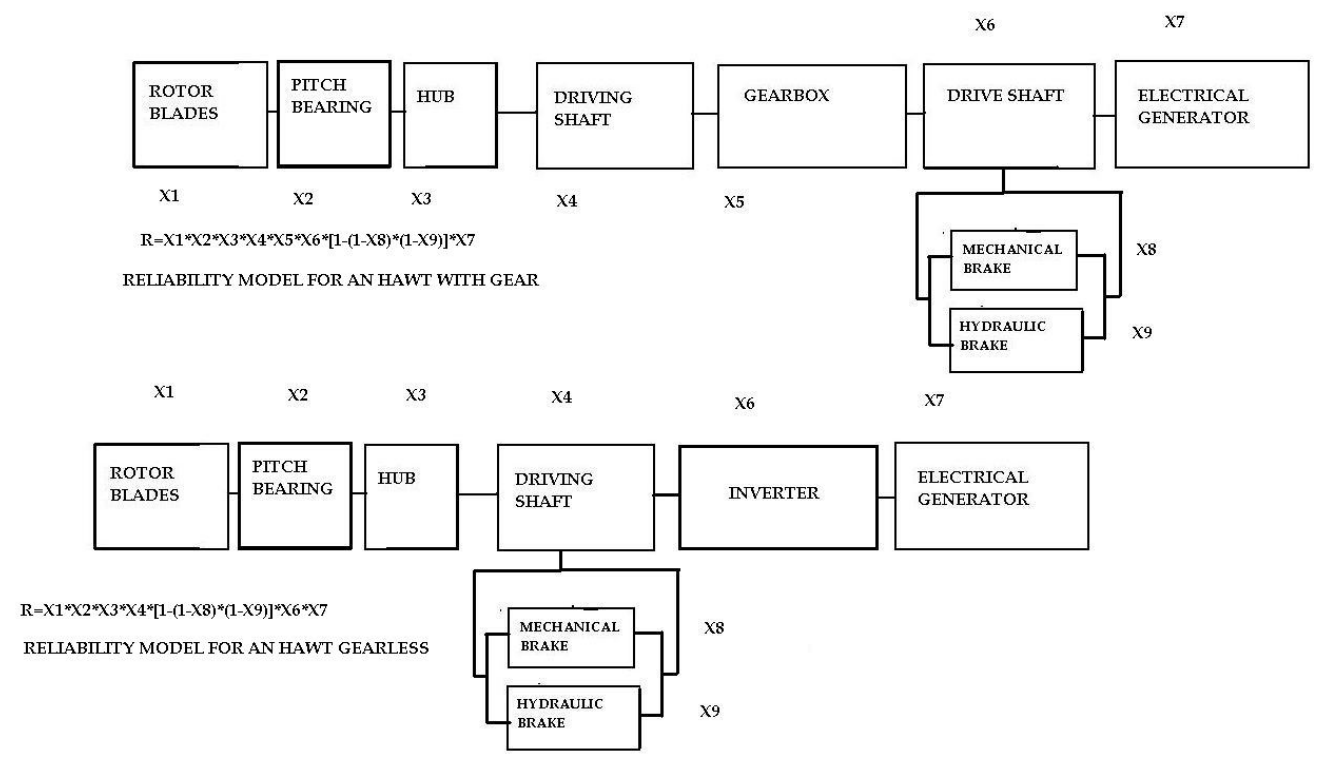

In the Figs. 6 and 7 the revision consists of the insert of reliability as structure function of the wind turbine axis line. 
Figure 8. Full drive train structure of an hawt

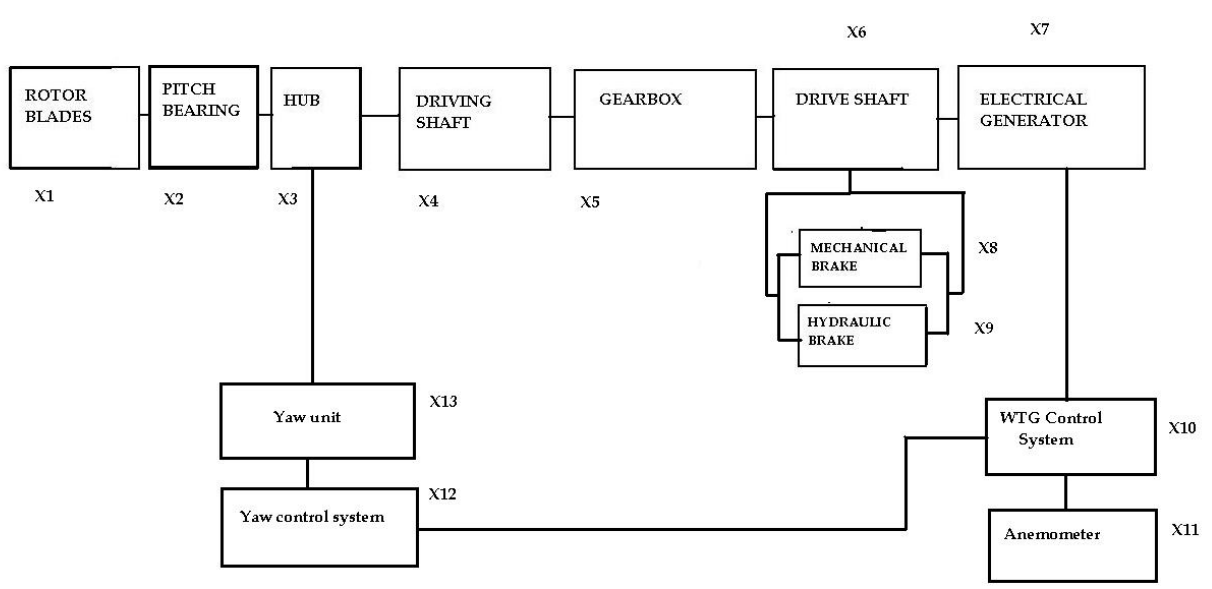

In Fig. 6, 7 and 8, close by the system structure, there are the $\mathrm{X}_{\mathrm{j}}$ value of the corresponding reliability of the specific component and, particularly, in Figs 6 and 7 the function $\Phi$ [see equation (4)]. As a result of the action carried out on HAWTs installed in harsch climate sites, the Fig. 9 show some structural damage to blade structure detected in an Italian site in Abruzzi Region.

Figure 9. Surfacial and structural damage for an hawt blade

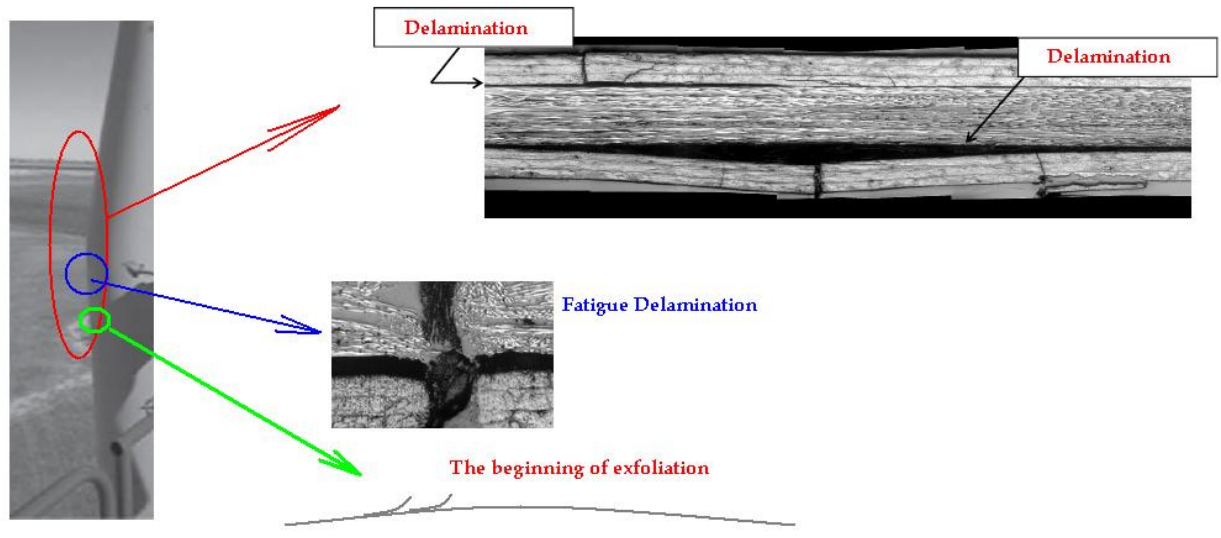


The damage is represented by fatigue delamination, exfoliation of the blade surface material.

The impacts of climatic conditions on wind turbine failures have been investigated in many studies as in [4] and [8]. Low temperatures could lead to lubricant freezing and brittleness in the components while temperature variations could cause expansions and contractions. Generally, high wind speed, turbulence and gust can produce lower reliability of wind turbine blade, pitch and mechanical drive train, whereas temperature and humidity affect electrical components rather than mechanical ones. The external factors such as lightning, icing and high winds increase the failure rate of wind turbines by 1.713 times. For the effects of weather conditions on wind turbine failures, winter is the season in which failure frequencies are increased and wind speed did not show any impact on failure occurrences. About $30 \%$ of the blade damage cases are caused by thunderstorms, followed by heavy rainfall with $28 \%$. Climatic conditions can not only have an impact on failure rates, but also affect the repair times of any failures, thus eventually causing variation in the resulting downtime. It is intuitive that repair time for a wind turbine in a snowy region when there is a heavy snowfall is not as the same as a region with no environmental obstacles for repair time. Particularly, we have observed as the failure rates and downtime values, based on different turbine types and aspects, show that direct-drive wind turbines failure rates in electrical and electronical components are greater than geared-drive wind turbines where gearbox failures cause the most downtime. Therefore, there is a need to determine the criticalities in these two different types of wind turbine. Really the impact may be very high in harsch climate sites as shown in following Tabs. Furtherly, the reliability of HAWTs may analysed using Second-Order Semi-Markov Chain as in [3] and for structural failure may be useful the procedure in [1] and also the other in [9].

\section{Failure data analysis}

Starting by the preliminary study as in [4], as previously exposed, we have collected data about failure rates, MTBF and downtime values for several WTGs in differente sites in Germany, North Europe Countries and in Italy, onshore and offshore, in mountainous areas and also in harsch climate sites.

The above mentioned data are shown in the following Tabs. 
Table 3. Data concerning of hawts taken into account in [4]

\begin{tabular}{|l|r|r|}
\multicolumn{3}{|c|}{ FAIIURE DATA ABOUT HAWTS IN OPERATIVE RUNNING SERVICE } \\
\hline \multicolumn{1}{|c|}{ Components or subsystems } & Failure rate & MTBF \\
\hline Drive train & 0,000418918 & $2.387,10$ \\
\hline Hydraulic systems & 0,001194643 & 837,07 \\
\hline Yaw control system & 0,001120561 & 892,41 \\
\hline HAWT structure & 0,000719088 & $1.390,65$ \\
\hline Blade and pitch bearing & 0,001120536 & 892,43 \\
\hline Hub & 0,000719036 & $1.390,75$ \\
\hline Electrical generator & 0,001826150 & 547,60 \\
\hline Electrical subsystems & 0,001828154 & 547,00 \\
\hline Gearbox & 0,000467290 & $2.140,00$ \\
\hline Mechanical Brake & 0,000839116 & $1.191,73$ \\
\hline Sensors & 0,001194001 & 837,52 \\
\hline
\end{tabular}

Table 4. Data about WTGs in Germany in [8] and [10]

\begin{tabular}{|l|r|r|}
\hline \multicolumn{4}{|c|}{ FAllURE DATA ABOUT HAWTS IN ONSHORE SITES (GERMANY) } \\
\hline \multicolumn{1}{|c|}{ Components or subsystems } & Failure rate & MTBF \\
\hline Drive train & 0,005707763 & 175,20 \\
\hline Hydraulic Systems & 0,001268392 & 788,40 \\
\hline Yaw Systems & 0,001426941 & 700,80 \\
\hline Structural parts & 0,002853881 & 350,40 \\
\hline Rotor Hub & 0,002283105 & 438,00 \\
\hline Rotor Blades & 0,001630789 & 613,20 \\
\hline Electrical Generator & 0,002853881 & 350,40 \\
\hline Electrical Systems & 0,000496327 & $2.014,80$ \\
\hline Sensors & 0,001141553 & 876,00 \\
\hline WTG Control Systems & 0,000634196 & $1.576,80$ \\
\hline Gearbox & 0,002853881 & 350,40 \\
\hline Mechanical Brake & 0,001902588 & 525,60 \\
\hline
\end{tabular}


Table 5. Downtimes in German Wind Farms from [8] and [5]

\begin{tabular}{|l|r|r|}
\hline \multicolumn{2}{|c|}{ DOWNTIMES OF SYSTEMS AND COMPONENTS (Germany) } \\
\hline \multicolumn{1}{|c|}{ Components or subsystems } & Downtime per failure (Days) \\
\hline Drive train & 6,00 \\
\hline Hydraulic Systems & 1,00 \\
\hline Yaw Systems & 3,00 \\
\hline Structural parts & 3,00 \\
\hline Rotor Hub & 3,50 \\
\hline Rotor Blades & & 4,00 \\
\hline Electrical Generator & 2,00 \\
\hline Electrical Systems & 2,00 \\
\hline Sensors & 2,00 \\
\hline WTG Control Systems & 3,50 \\
\hline Gearbox & 6,00 \\
\hline Mechanical Brake & 3,00 \\
\hline
\end{tabular}

Table 6. Downtimes in hawts operating in harsch climate sites from [4] and [8]

\begin{tabular}{|l|r|}
\hline \multicolumn{2}{|c|}{ DOWNTIMES OF SYSTEMS AND COMPONENTS (Mountainous and harsch climate areas) } \\
\hline \multicolumn{1}{|c|}{ Components or subsystems } & Downtime per failure (Days) \\
\hline Drive train & 30,00 \\
\hline Hydraulic Systems & 27,00 \\
\hline Yaw Systems & 10,00 \\
\hline Structural parts & 5,00 \\
\hline Rotor Hub & 40,00 \\
\hline Rotor Blades & 45,00 \\
\hline Electrical Generator & 100,00 \\
\hline Electrical Systems & 65,00 \\
\hline Sensors & 50,00 \\
\hline WTG Control Systems & 24,00 \\
\hline Gearbox & 43,00 \\
\hline Mechanical Brake & 100,00 \\
\hline
\end{tabular}

The data shown in Tab. 3 concern of wind turbines failures in the analysed Italian wind farms, while data in Tabs. 4 and 5 concern wind turbines in German sites. The Tab. 6 shows data about the downtimes detected in German and Italian sites with the same wind turbine type (Micon, Nordex and Vestas about $2 \mathrm{MW}$ in rated power).

On the contrary, in Tab. 6 recent data (2015-2018) about Italian and German sites are exposed. They show as the larger downtime is due to mechanical systems thet in mountainous areas may have a particular failure sensitivity.

In the Tab. 7 recent data (2017-2019) about some Italian wind farms in mountainous sites are exposed: according to them the drive train failures and the yaw systems ones are the larger and 
by analysis od SCADA system data the main cause appears as the gusts suffered during winter storms and the grid failures during the same period. Gearbox failures have caused great damages to drive train and, particularly, to the electrical generator increasing the global downtime as yet.

Table 7. Recent data about downtimes in Italian wind farms

\begin{tabular}{|l|r|r|}
\hline \multicolumn{3}{|c|}{ DOWNTIMES OF SYSTEMS AND COMPONENTS (Mountainous areas - Italy) } \\
\hline \multicolumn{1}{|c|}{ Components or subsystems } & MTBF (h/year) & Downtime per failure (Days) \\
\hline Drive train & 2850 & 150,00 \\
\hline Hydraulic Systems & 4578 & 185,00 \\
\hline Yaw Systems & & \\
\hline Structural parts & 3500 & 43,00 \\
\hline Rotor Hub & & \\
\hline Rotor Blades & 1250 & 3,00 \\
\hline Electrical Generator & & \\
\hline Electrical Systems & 7500 & \\
\hline Sensors & & \\
\hline WTG Control Systems & & \\
\hline Gearbox & & \\
\hline Mechanical Brake & & \\
\hline
\end{tabular}

The annual failure rate (AFR) is defined as the average number of failures per year and the corresponding data are shown in Tab. 8.

Table 8. AFR data concerning of wind farms analysed in [5] and [8]

\begin{tabular}{|l|r|r|}
\hline \multicolumn{3}{|c|}{ ANNUAL FAILURE RATE VS. WIND FARM SITES AND CLIMATE CONDITIONS } \\
\hline \multicolumn{1}{|c|}{ Components or subsystems } & ONSHORE SITES (Mountain) & OFFSHORE SITES \\
\hline Drive train & 0,050 & 0,060 \\
\hline Hydraulic Systems & 0,210 & 0,300 \\
\hline Yaw Systems & 0,189 & 0,211 \\
\hline Structural parts & 0,090 & 0,100 \\
\hline Rotor Hub & 0,210 & 0,185 \\
\hline Rotor Blades & 0,150 & 0,105 \\
\hline Electrical Generator & 0,100 & 0,110 \\
\hline Electrical Systems & 0,600 & 0,610 \\
\hline Sensors & 0,300 & 0,250 \\
\hline WTG Control Systems & 0,450 & 0,420 \\
\hline Gearbox & 0,100 & 0,134 \\
\hline Mechanical Brake & 0,116 & 0,156 \\
\hline
\end{tabular}


Starting from downtimes data, it's possible to assess reliability values for subsystems and components, as in Tab. 9, and, then, from equation (3), (4), (5) and (6) analyse the HAWT reliability.

The resulting value for the HAWT global reliability is shown in Tab. 10 where the reliability value for every site-type results from the analysis of collected data about mainteinance of several wind farms.

Table 9. Reliability values assessment for hawt subsystems and components

\begin{tabular}{|l|r|r|}
\hline \multicolumn{3}{|c|}{ RELIABIITY OF SYSTEMS AND COMPONENTS (Mountainous and harsch climate areas) } \\
\hline \multicolumn{1}{|c|}{ Components or subsystems } & Downtime per failure (Days) & Reliability value \\
\hline Drive train & 30,00 & 91,78 \\
\hline Hydraulic Systems & 27,00 & 92,60 \\
\hline Yaw Systems & 10,00 & 97,26 \\
\hline Structural parts & 5,00 & 98,63 \\
\hline Rotor Hub & 40,00 & 89,04 \\
\hline Rotor Blades & 45,00 & 87,67 \\
\hline Electrical Generator & 100,00 & 72,60 \\
\hline Electrical Systems & 65,00 & 82,19 \\
\hline Sensors & 50,00 & 86,30 \\
\hline WTG Control Systems & 24,00 & 93,42 \\
\hline Gearbox & 43,00 & 88,22 \\
\hline Mechanical Brake & 100,00 & 72,60 \\
\hline
\end{tabular}

Table 10. HAWTs reliability values assessment

\begin{tabular}{|l|r|r|}
\hline \multicolumn{1}{|c|}{ RELIABIITY OF HAWTs Assessment (Mountainous and harsch climate areas) } \\
\hline \multicolumn{1}{|c|}{ Sites } & HAWT with gearbox & \multicolumn{1}{c|}{ Gearless HAWT } \\
\hline & 0,96 & 0,97 \\
\hline Onshore (hill) & 0,91 & 0,93 \\
\hline & & \\
\hline Onshore (Mountainous areas) & 0,97 & 0,98 \\
\hline & & \\
\hline Offshore sites & & \\
\hline
\end{tabular}

In Tab. 10 reliability assessment has been proposed as result of eq. (4) and referring to the wind turbine structures in Fig. 8.

These values represent the functional objective that mainteinance should assure for wind turbines in the corresponding sites and the related environmental conditions. 


\section{Conclusions}

The climate conditions sites and the type of HAWT drive train affects machine reliability in a remarkable way, and, generally, the best values are reached by gearless wind turbine.

In several mainteinance actions the Author has detect as reliability analysis results are not taken into account, probably for a kind of different organization, but this fact doesn't result in a good efficiency.

The MTBF data may be very useful in organizing preventive mainteinance and the reliability assessment according eq. (2) may useful to know the specific reliability and the MTBF expected value if failure rate is constant.

A larger use of mainteinance procedures based on reliability analysis may be very useful particularly in wind farms offshore, in mountainous areas and in adverse climate conditions.

A greater diffusion of these procedures among the companies that deal with maintenance would be very important to reduce intervention times and the global mainteinance duration.

In this way, downtimes may be reduced with a lower lost in energy pruduction (LEP).

Also a reduction in AFR value using higher quality components may be very useful. To reach this objective the reliability assessment based on eq. (4) may be useful.

As above shown, wind turbines achieve an excellent technical availability of about $98 \%$ on average, although they have to face a high number of malfunctions.

It can be assumed that these good availability figures can only be achieved by an high number of service teams who respond to turbine failures within short time.

Furtherly, in order to improve the reliability of WTs, the designers have to better the choice of electric and electronic components.

This is particularly true and absolutely necessary in the case of new and large turbines, expecially for machines operating in adverse and hasch climate conditions sites.

\section{References}

[1] ADAMS, D. et Al. (2011) : Structural health monitoring of wind turbines : method and application to a HAWT, in Wind Energy, 2011, 14, pp. 603-623;

[2] BRESS, T. J. (2017): Wind turbine reliability, in Electrical Engineering \& Computer Science Article, June 2017, pp. 5;

[3] D'AMICO, G. et Al. (2013): Reliability measures of Second-Order Semi-Markov Chain Applied to Wind Energy Production, in Hindawi Publ. Co. - Journal of Renewable Energy, Vol. 2013, Article ID 368940, pp. 6;

[4] DE PRATTI, G.M. (2002): Analisi dei problemi di affidabilità degli aerogeneratori operanti in ambiente aggressivo, in Proc. of the 7th ANIV Conference, Milan, 15-18.09.2002, pp. 523.529; 
[5] FAULSTICH, S. et Al. (2011) : Wind Turbine downtime and its importance for offshore deployment, in Wind Energy, 2011, 14, pp. 327-337;

[6] HAHN, B. et Al. (2006) : Reliability of Wind turbines, Kassel (Germany), ISET, pp. 4;

[7] IRESON, W. G. - COOMBS, C. F. jr. (1988): Handbook of Reliability Engineering and Management, New York, McGraw-Hill Ed., pp. 400;

[8] OZTURK, S. et Al. (2018): Failure Modes, Effects and Criticality Analysis for Wind Turbines Considering Climatic Regions and Comparing Geared and Direct Drive Wind Turbines, in Energies 2018, 11, 2317 ; doi : 10.3390/en11092317, pp. 18;

[9] SARANYASOONTORN, K. and Manuel, L. (2005): On Assessing the Accuracy of Offshore Wind Turbine Reliability-based Design Loads from the Environmental Contorur Method, in Int. J. of Offshore and Polar Engineering, Vol. 15, No. 2, June 2005, pp. 1-9;

[10] WILKINSON, M. et Al. (2011) : Measuring Wind Turbine Reliability - Results of the Reliawind Project, Final Rep. Of the EU FP7 Project RELIAWIND 212966, pp. 8;

[11] WH - ABB (2011): Wind Energy Handbook n 13, ABB, in library.e.abb.com, pp. 136. 